\title{
Effects of Aquatic Motor Activities on Early Childhood Cognitive and Motor Development
}

\author{
Michal Nissim¹, Ronit Ram-Tsur1', Michal Zion, Tal Dotan Ben-Soussan²,3, \\ Zemira Mevarech1 \\ ${ }^{1}$ School of Education, Bar-Ilan University, Ramat Gan, Israel \\ ${ }^{2}$ The Gonda (Goldschmied) Multidisciplinary Brain Research Center, Bar-Ilan University, Ramat Gan, Israel \\ ${ }^{3}$ Patrizio Paoletti Foundation for Development and Communication, Assisi, Italy \\ Email: Michal.beren@gmail.com
}

Received 19 October 2014; revised 21 November 2014; accepted 28 November 2014

Copyright (C) 2014 by authors and Scientific Research Publishing Inc.

This work is licensed under the Creative Commons Attribution International License (CC BY). http://creativecommons.org/licenses/by/4.0/

c) (i) Open Access

\begin{abstract}
While the mental and physical benefits of motor activity are well documented, the degree to which these benefits are dependent upon the environment within which the activity takes place remains unknown. Specifically, studies exploring the effects of aquatic motor activities on cognitive abilities are rare. The current study investigated the effects of aquatic motor activities-as compared to on-land motor activities and non-motor activities-on the development of motor and cognitive abilities in a sample of 94 children aged between four and six. Developmental-functionality testsincluding fine and gross motor, time estimation, reasoning and processing speed tests-were used to measure the motor and cognitive abilities of participants before and after six months of intervention. Participation in the aquatic motor activities group was found to improve gross motor, time-estimation and reasoning abilities. Moreover, improvements in gross motor abilities mediated the association between participation in aquatic motor activities group and the children's processing speed ability. These findings can improve the understanding of child development professionals, psychologists and educators regarding the connection between aquatic environment and cognitive and motor development, and may contribute to improved early childhood interventions.
\end{abstract}

\section{Keywords}

Early Childhood Development, Motor Intervention, Cognitive Change, Aquatic Environment 


\section{Introduction}

There are well-documented cognitive and physical benefits from physical activity, throughout life and across diverse population groups [1]-[3]. Furthermore, it has been posited that compromised neuropsychological functioning is associated with impaired cognitive and motor development [4]. Thus, early childhood professionals are in agreement concerning the importance of motor development and physical activity in the cognitive and neural development of children [5]. For example, Sibley and Etnier [6] found in their research review a significant positive relation between physical activity and cognitive functioning in children aged between 4 and 18 years. More specifically, they concluded that physical activity improves children's perceptual skills, verbal abilities and developmental levels. Hillman, Erickson and Kramer [7] suggested that exercise during early childhood is important for the development of cognitive health. Every child has a unique developmental pattern, they propose, and individual development will be influenced by the interaction between life experiences and the environment within which these experiences occur. For example, according to the Dynamic System Theory (DST), the interaction between the individual, the purpose of the task and the environmental conditions contribute to the child development [8]. This theory will underpin the current study, in that we contend that it is theoretically possible to effect an improvement in existing skills — or even introduce new ones - by changing the environment in which a specified activity occurs. The unique environment that we explored was water, and we determined to compare aquatic motor activities with on-land motor activities in order to test this hypothesis.

Water has been used throughout history for a variety of purposes, including physical therapy, rehabilitation and sport. These activities are made possible by water's special qualities and the influence of these attributes on humans [9]. Through immersion in an aquatic environment, a child can be exposed to new skills - such as swimming, diving and floating - which can't be performed on land. Aquatic motor activity (AMA) exposes the child to unique sensorimotor stimuli, including floating boards and sinking objects, which can only be employed in an aquatic environment. In addition, AMA provides multi-sensory stimulation combining three sensory systems - the vestibular, proprioceptional and tactile. In turn, these forms of multi-sensory stimulation may improve balance and coordination [10]. More specifically, multi-sensory stimulation by way of immersion can improve balancing abilities by increasing the proprioceptive input to the immersed body, thus providing greater body alignment and stability. Sensory feedback is increased by promoting a sense of body awareness, as resistance to movement through water is greater than resistance through air [11]. Moreover, sensorimotor integration may be stimulated more effectively in an aquatic environment in comparison to an on-land environment, since water provides three dimensions of movement-forward-backward, up-down and right-left. The experience of these spatial concepts depends on the body of each individual and how that body learns to interact with its surroundings [12]. A recent study, which used functional near-infrared spectroscopy to investigate the influence of water immersion on cortical activation, found that aquatic immersion induced cortical activation in both the somatosensory and motor areas, suggesting that aquatic immersion might enhance motor learning during the period of acquisition of motor skills [13].

The integration of the sensorimotor information learned in controlling the aquatic environment during motor activities - such as floating and diving - is made possible by the concept of neuroplasticity, which enables the development of a network of neural connections as a response to experience [14]. Upon repetition, these neural groups create communication patterns which in time develop into neural paths. Neuroplasticity is known to be particularly high in early childhood [15].

One of the most investigated areas examined in relation to neuroplasticity is the cerebellum [16]. The cerebellum has long been known to be involved in the coordination and automatisation of movements, in balance and posture and in motor-learning [17] [18] in addition to its important role in sensorimotor integration [19] [20]. Several studies have shed light on additional functions of the cerebellum, which include complex cognitive operations [16] [21]. For example, activation of the cerebellum has repeatedly been found to be an aspect of several working-memory and reasoning abilities tasks [22]-[25]. Other evidence has indicated the importance of the cerebellum in timing processes [26], such as in time estimation [27] [28]. Time estimation is an important component of the ability to organize and plan sequences of actions [29] [30]. In addition, time estimation (specifically, temporal discrimination ability) has been found to correlate with the cognitive ability (specifically, measurements of the successes rate in Ravens' Advanced Progressive Matrices test) of undergraduate students [31].

Over the last two decades, researchers have discussed the "cerebellar deficit hypothesis of dyslexia" [32] [33], suggesting that cerebellar deficits in the timing functioning which interfere with the automatisation of function 
development can lead to problems in articulation and working memory. One of the most well-known studies supporting this hypothesis used fine-motor tasks, including finger-to-thumb and bimanual finger-tapping, in which dyslexic teenagers showed lower performances than control participants in the study, to demonstrate these consequences [34]. Another study found low performance in time-estimation tasks among dyslectic children as compared to control participants [35]. A recent brain-imaging study found a reduced volume in the anterior lobe of the cerebellum of children with decoding impairments (namely, dyslexia) in comparison to typically-developing children. Recent studies have found cerebellar functional activation patterns during reading and motor learning in dyslexic readers. Some children and adults with dyslexia show poorer performance in cerebellar motor tasks, including eye-movement control, postural stability and implicit motor learning [21]. These results indicate cerebellar involvement in dyslexia and establish an important foundation for future research concerning the connectivity of the cerebellum and cortical regions typically associated with reading impairment [36].

Nonetheless, the connection between the cerebellum, sensorimotor processing and cognitive abilities requires further investigation. Despite the studies mentioned above, there is a dearth of research comparing the effects of motor training in differing environments - such as water - on cognitive development. Moreover, there has been very little research about the contribution of AMA to areas of functioning that are not physiological or motorrelated. Thus, in the current study, we examined the relation between gross-motor, fine-motor and time-estimation abilities, and the possible connection between these abilities and cognitive abilities such as reasoning and processing speed. To do so effectively, we combined existing knowledge of motor- and cognitive-related research regarding the effects of AMA. Based on the above findings, we made the following hypotheses regarding the advantages of AMA as compared to On-Land Motor Activity (OLMA) and Non-Motor Activity (NMA): (a) AMA would have a higher positive effect on gross motor abilities, as compared to the effects of OLMA and NMA; (b) AMA would have a higher positive effect on fine motor abilities, as compared to the effects of OLMA and NMA; (c) AMA would have a higher positive effect on time estimation abilities, as compared to the effects of OLMA and NMA.

Since children with automaticity and coordination in motor abilities may have a greater processing capacity available to learn more complex concepts such as symbolic representation [37] and since the aquatic environment may enhance motor learning [13], we further hypothesized that (d) AMA would have a higher positive effect on cognitive abilities, as compared to the effects of OLMA and NMA and (e) changes in gross motor, fine motor and time-estimation abilities will mediate the effects on cognitive abilities.

\section{Method}

\subsection{Participants and Procedure}

To aid comprehension of the study's design, a flow diagram (Figure 1) has been employed according to the CONSORT (Consolidated Standards of Reporting Trials) statement (http://www.consort-statement.org/). The flow diagram is intended to depict the participants' state of information awareness during the four stages of the trial, incorporating enrollment, intervention allocation, follow-up and analysis.

The participants were recruited from a regional kindergarten complex, serving children between the ages of four and six years from middle socioeconomic status families (according to The Central Bureau of Statistics, Local Authorities in Israel 2010, Publication No. 1). The research was approved by the Chief Scientist of the Israeli Ministry of Education, and by the Ethics Committee of Bar-Ilan University. Participants in the study were recruited between September 1 and October 31, 2011. Parents of potential research participants were asked to complete a developmental and background questionnaire. Criteria for the children's eligibility included (a) normal birth weight, (b) normal motor, cognitive and language development, (c) normal hearing, (d) no absences from kindergarten, of longer than one week in duration, up until October 31, 2011 and (e) participation in only one additional extracurricular activity provided by the local community center after October 31, 2011.

The children were divided at random into three intervention groups. Assessments of the motor, time-estimation and cognitive abilities of the children were conducted during personal meetings prior to the commencement of the intervention activities, and again with exactly the same diagnostic battery of tests after six months of participation in one of the activities. The activity procedure (AMA, NMA or OLMA) was delivered in the form of a weekly training session of 45 minutes in duration. We compared the effects of AMA with two control groups: the NMA group was chosen in order to provide a control for the motor aspects of the training, while the OLMA 


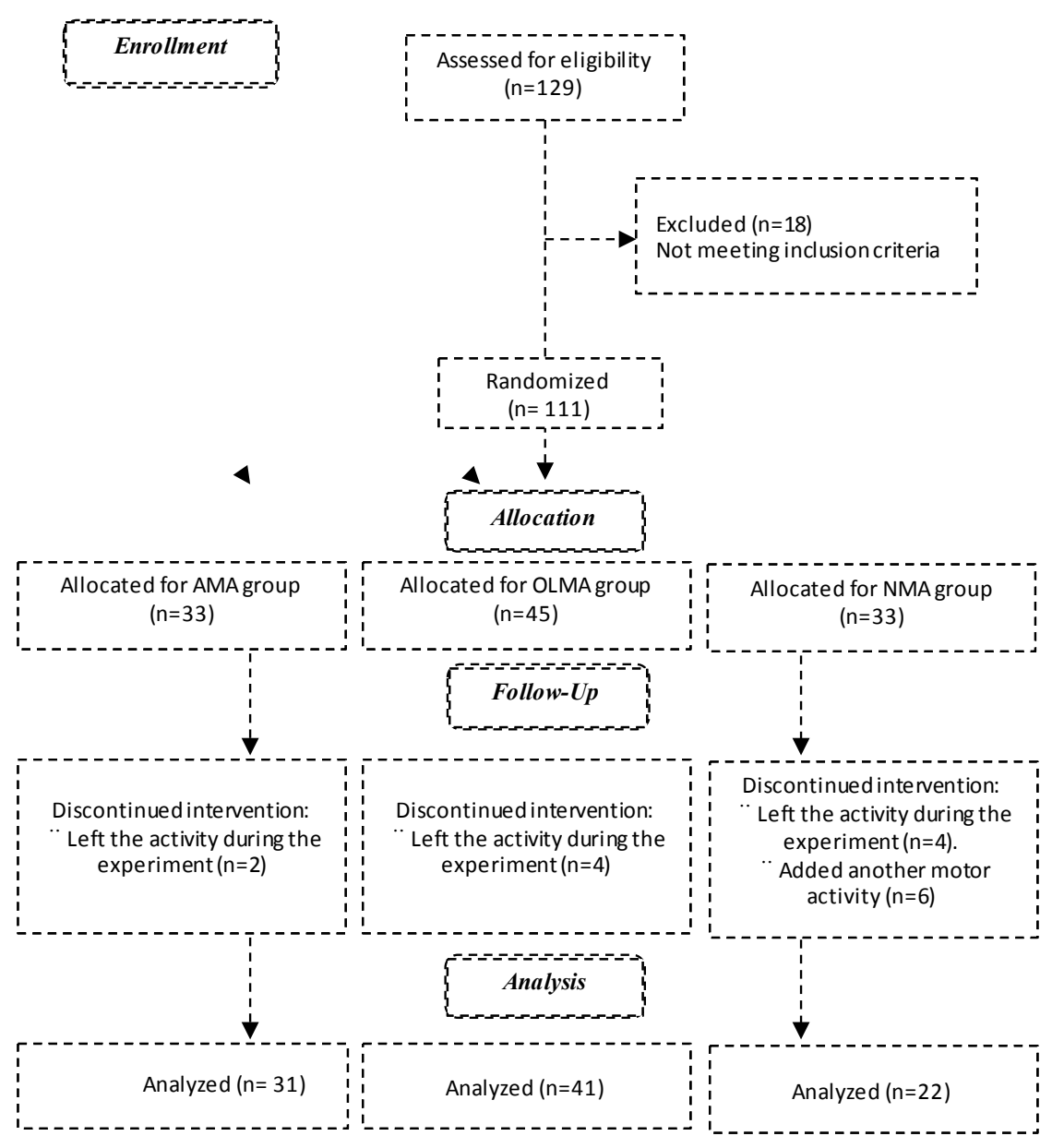

Figure 1. Flow diagram of a randomized trial for evaluating effects of intervention on motor and cognitive abilities during early childhood. The diagram includes information on the excluded participants.

group was chosen in order to provide a control for the environmental aspect of the training.

\subsection{Training Groups}

Aquatic Motor Activities (AMA): The AMA took place in a hydrotherapy pool (14 meters long and 5 meters wide, temperature maintained at $33^{\circ} \mathrm{C}$, with a pool depth range ranging from 80 centimeters to 140 centimeters). One swimming instructor accompanied up to five children in the pool. The children learned how to exercise control over their aquatic environment through activities such as standing and walking in water up to the chest, floating on the back/stomach, rolling over from stomach to back (and vice versa) while kicking with legs and moving hands, and diving. We used the basic rotational exercises of the Halliwick method [38] [39]. This method is based on scientific principles of hydrodynamics and body mechanics, and is divided into 4 phases: adjustment to water; rotations; control of movement in water; and movement in water.

On-Land Motor Activities (OLMA): The second intervention group was made up of children who participated in OLMA (basketball, football, judo, general gymnastics and ballet). One instructor accompanied five children.

Non-Motor Activities (NMA): The third intervention group was made up of children who participated in no explicitly targeted motor activities (chess, drama and art). One instructor accompanied five children.

\subsection{Tasks}

The Gross Motor Protocol Included the Following Test:

The Test of Gross Motor Development [40]: This test assesses the quality and quantity of movement in child- 
ren, and has been used to assess change as a function of increasing age, experience, instruction or intervention. We used a version adapted for use in Israel [41] [42]. The test includes locomotion and object control abilities. The locomotion section of the test consists of four consecutive items: running, horizontal jumping, sliding and galloping. The object control subtest consists of four consecutive items: catching, kicking, bouncing and overhand throwing. An accurate demonstration and verbal description of the task required was provided beforehand by an experienced adult. The child was allowed one practice attempt, to ensure comprehension. If the child did not appear to understand the explanation or did not perform the practice attempt correctly, an additional demonstration and instructions were provided. Each child then performed three repetitions of each gross motor skill; first all the locomotion subtest abilities, and then all the object control abilities. Each time the task was performed correctly, a score of 1 was given; incorrect performances of the task were scored 0 . The sum of all performances represents the final score for each item. Internal consistency reliability for the locomotion and object control score, and also for the total composite score, averaged $0.78,0.74$ and 0.80 respectively. The measure of the outcome was the score for each part.

The Fine Motor Protocol Included the Following Tests:

Finger-to-Thumb Test [17]: The child was asked to place the index finger of one hand onto the thumb of the other hand and vice-versa. Then, keeping the top thumb and finger together, the child was asked to rotate one hand clockwise and the other anti-clockwise until finger and thumb touched again. The task was demonstrated, and subjects practiced the tasks until they were able to complete the movement fluently five times in succession. They were then asked to perform ten movements as quickly as possible. The measure of the outcome was the time taken for ten successive movements.

Repetitive Finger Tapping [43]: The child was asked to press the button on a response box with the index finger, repeatedly and as quickly as possible, for one minute. Each press of the button was recorded, and the outcome was the average duration between two depressions and the total number of depressions of the button.

The Time-Estimation Protocol Included the Following Test:

The Time-Estimation Test was inspired by the test of Nicolson and colleagues [35], itself inspired by Ivry and Keele [27]. In each time-estimation trial two tones were presented successively, and the child was asked to indicate whether the second tone was longer or shorter than the first. The standard stimulus, always presented first, was a 1200 millisecond-long pure tone of frequency $392 \mathrm{~Hz}$. Fifteen comparison tones had respective durations of 400, 700, 800, 900, 950, 1000, 1050, 1200, 1350, 1400, 1450, 1500, 1600, 1700 and 2000 milliseconds (ms). The two tones were separated by a $1000 \mathrm{~ms}$ silent interval. Each trial was performed twice, amounting to 30 test trials presented in random order. The test block was preceded by a practice block of eight trials (using only the eight extreme comparison tones), during which feedback was provided. No feedback was provided during the test block. The stimuli were transmitted by a computer through headphones at about $75 \mathrm{~dB}$ SPL. After each pair of tones, the subjects indicated whether the second tone was longer or shorter than the first one. The measure of the outcome was the number of correct answers.

The Cognitive Protocol Included the Following Tests:

The Raven's Colored Progressive Matrices (RCPM) [44]: This is a well-known assessment battery of nonverbal visual reasoning abilities, using the ability to match appropriate colors and patterns. The RCPM consists of three sets, A, Ab, and B. Each subset contains 12 items, and each item consists of a drawing (matrix) of a pattern from which a section is missing. At the bottom of the page, six patterns are printed, one matching the missing section. The child was to choose which of the six alternatives fits the missing section. Internal consistency reliability is 0.90 . The outcome was measured by the number of correct answers.

Visual Matching [45]: This test measures the ability to demonstrate visual discrimination by circling pairs of identical numbers in a row of six numbers as quickly as possible. The child was given two minutes to complete the test. Internal consistency reliability is 0.96 . The outcome was measured by the number of correct answers.

Cross Out [45]: This test measures the ability to make quick comparisons of visual symbols. The child has to identify five identical shapes in a row of 19 shapes as quickly as possible. The child was given two minutes to conduct the test. Internal consistency reliability is 0.90 . The outcome was measured by the number of correct answers.

\subsection{Data Analysis}

The groups were compared against background characteristics (see Table 1) and baseline scores of tests (see Table 2). No significant differences were found between the groups. 
Table 1. Characteristics and demographic descriptions of study participants.

\begin{tabular}{|c|c|c|c|c|}
\hline & $\begin{array}{c}\text { AMA } \\
\mathrm{n}=31 \\
\mathrm{M}(\mathrm{SD})\end{array}$ & $\begin{array}{c}\text { OLMA } \\
\mathrm{n}=41 \\
\mathrm{M}(\mathrm{SD})\end{array}$ & $\begin{array}{c}\text { NMA } \\
\mathrm{n}=22 \\
\mathrm{M}(\mathrm{SD})\end{array}$ & $F(2,91)$ \\
\hline Raven's Colored Progressive Matrices & $\begin{array}{l}12.87 \\
(3.24)\end{array}$ & $\begin{array}{l}13.56 \\
(3.12)\end{array}$ & $\begin{array}{l}13.00 \\
(2.89)\end{array}$ & 0.70 \\
\hline Age in months & $\begin{array}{c}57.2 \\
(7.81)\end{array}$ & $\begin{array}{c}57.1 \\
(8.52)\end{array}$ & $\begin{array}{c}53.5 \\
(7.54)\end{array}$ & 0.18 \\
\hline Mother education ${ }^{\mathrm{a}}$ & $\begin{array}{c}1.83 \\
(0.37)\end{array}$ & $\begin{array}{c}1.90 \\
(0.30)\end{array}$ & $\begin{array}{c}1.86 \\
(0.35)\end{array}$ & 0.77 \\
\hline \multicolumn{5}{|l|}{ Gender } \\
\hline Male & $\begin{array}{c}15 \\
(48.4 \%)\end{array}$ & $\begin{array}{c}19 \\
(46.5 \%)\end{array}$ & $\begin{array}{c}12 \\
(54.5 \%)\end{array}$ & \\
\hline Female & $\begin{array}{c}16 \\
(51.6 \%)\end{array}$ & $\begin{array}{c}22 \\
(53.5 \%)\end{array}$ & $\begin{array}{c}10 \\
(45.5 \%)\end{array}$ & \\
\hline
\end{tabular}

${ }^{\mathrm{a}}$ Calculated on a 4-point scale: 1 = graduate high school; 2 = graduate B.A; 3 = graduate M.A; 4 = graduate Ph.D.

Table 2. Differences between study group in gross motor, fine motor and cognitive abilities at baseline.

\begin{tabular}{|c|c|c|c|c|}
\hline & $\begin{array}{c}\text { AMA } \\
\mathrm{n}=31 \\
\mathrm{M}(\mathrm{SD})\end{array}$ & $\begin{array}{c}\text { OLMA } \\
\mathrm{n}=41 \\
\mathrm{M} \text { (SD) }\end{array}$ & $\begin{array}{c}\text { NMA } \\
\mathrm{n}=22 \\
\mathrm{M} \text { (SD) }\end{array}$ & $F(2,91)$ \\
\hline Locomotion & $\begin{array}{l}14.06 \\
(1.88)\end{array}$ & $\begin{array}{l}13.83 \\
(2.64)\end{array}$ & $\begin{array}{l}13.27 \\
(2.03)\end{array}$ & 0.41 \\
\hline Object control & $\begin{array}{l}13.03 \\
(1.33)\end{array}$ & $\begin{array}{l}12.51 \\
(2.68)\end{array}$ & $\begin{array}{l}12.00 \\
(2.23)\end{array}$ & 0.21 \\
\hline Finger-to-thumb & $\begin{array}{l}16.47 \\
(7.27)\end{array}$ & $\begin{array}{c}19.59 \\
(16.05)\end{array}$ & $\begin{array}{c}25.39 \\
(10.17)\end{array}$ & 0.09 \\
\hline Repetitive finger tapping & $\begin{array}{l}103.09 \\
(16.49)\end{array}$ & $\begin{array}{l}105.44 \\
(19.69)\end{array}$ & $\begin{array}{c}94.95 \\
(20.87)\end{array}$ & 0.11 \\
\hline Time-estimation & $\begin{array}{l}19.42 \\
(3.18)\end{array}$ & $\begin{array}{l}18.70 \\
(3.87)\end{array}$ & $\begin{array}{l}17.59 \\
(3.38)\end{array}$ & 0.15 \\
\hline Visual matching & $\begin{array}{c}5.14 \\
(2.53)\end{array}$ & $\begin{array}{c}4.88 \\
(3.19)\end{array}$ & $\begin{array}{c}3.53 \\
(3.03)\end{array}$ & 0.10 \\
\hline Cross out & $\begin{array}{c}2.87 \\
(1.22)\end{array}$ & $\begin{array}{c}3.07 \\
(1.81)\end{array}$ & $\begin{array}{c}2.23 \\
(1.57)\end{array}$ & 0.13 \\
\hline
\end{tabular}

Notes: All categories measured at baseline.

In order to investigate our first four hypotheses regarding the differences between the effect of Study Group (AMA, OLMA, and NMA) on gross motor abilities (locomotion and object control), fine motor abilities (fingerto-thumb, tapping average and tapping ability), time-estimation ability, and cognitive abilities (visual matching, cross-out, RCPM), we conducted a series of mixed analyses of variance, in which the Study Group served as the between-subject independent variable and Time served as the within-subject independent variable. The dependent variables were the tasks (separately for each task). In order to investigate our last hypothesis-if the changes in gross motor abilities, fine motor abilities and time-estimation ability mediated the effect of training groups on cognitive abilities - we employed mediation analyses, following Preacher and Hayes's [46] procedure. This procedure follows Baron and Kenny's [47] four-step method, where progression from one step to the next is contingent on obtaining significant results in the preceding step. In the first step, we examined whether the study group (X: the predictor) predicted the change in the motor and time-estimation abilities (M: the mediators). In the second step, we examined whether the change in the motor and time-estimation abilities predicted the change 
in cognitive abilities (Y: the outcomes) when controlled for the effect of the study group. In the third step, we examined whether the mediation paths from the study group, via the change in the motor and time-estimation abilities, to the change in cognitive abilities were significant.

A significant bias-corrected bootstrap analysis would support mediation. Finally, in the fourth step, we examined whether the direct links from the training group to the change in cognitive abilities remained significant when controlled for the change in the motor and time-estimation abilities. A significant direct link would support partial mediation, whereas a non-significant link would support full mediation. In the present analyses, we gave up Baron and Kenny's [47] traditional first step - in which one needs to establish a significant direct link from the predictor to the outcome variable [48].

\section{Results}

\subsection{Differences between Study Groups in Gross Motor Abilities}

A significant Time by Group interaction was observed in both the locomotion $[F(2,91)=6.90, p<0.05]$ (see Figure 2(a)) and object control $[F(2,91)=3.30, p<0.05]$ abilities (see Figure 2(b)). The locomotion abilities improved over time only among the AMA $(t(30)=-5.29, p<0.01)$ and OLMA $(t(40)=-3.22, p<0.01)$ groups, but not among the NMA group $(t(21)=-0.23, p>0.05)$. The object control abilities improved over time only among the AMA $(t(30)=-6.44, p<0.01)$ and $\operatorname{OLMA}(t(40)=-2.14, p<0.05)$ groups, but not among the NMA group $(t(21)=-0.33, p>0.05)$. Bonferroni post-hoc analyses indicated that the AMA group achieved a better improvement in the locomotion and object control scores over time than the NMA group. The OLMA group did not differ significantly from either group.

\subsection{Differences between Study Groups in Fine Motor Abilities}

No significant Time by Group interactions was observed in all of the fine motor tasks.

\subsection{Differences between Study Groups in Time Estimation Ability}

A significant Time by Group interaction was observed in the time estimation ability $[F(2,91)=6.09, p<0.01]$ (see Figure 3$)$. The time estimation ability improved over time only among the AMA $(t(30)=-6.21, p<0.001)$ and OLMA $(t(40)=-3.46, p<0.01)$ groups, but not among the NMA group $(t(21)=-1.30, p>0.05)$. Bonferroni post-hoc analyses indicated that the AMA group achieved a better improvement in the time estimation score than the NMA group. The OLMA group did not differ significantly from either group.

\subsection{Differences between Study Groups in Cognitive Abilities}

A significant Time by Group interaction was observed in the RCPM score $[F(2,91)=33.09, p<0.01]$ (see Figure 4). The RCPM score improved over time only among the AMA $(t(30)=-12.51, p<0.001)$ and OLMA $(t(40)=-2.86, p<0.01)$ groups, but not among the NMA group $(t(21)=-0.18, p>0.05)$. Bonferroni post-hoc analyses indicated that the AMA group achieved a better improvement in the RCPM score than the NMA group. The OLMA group did not differ significantly from either group. No other significant Time by Group interactions was observed in the cognitive tasks.

\subsection{Does the Change in Gross Motor, Fine Motor and Time-Estimation Abilities Mediate the Effect Study Group on the Cognitive Abilities}

Step I. To examine whether the AMA group predicts changes in the gross motor, fine motor and time-estimation abilities, we first effect-coded the study group variable. This coding enabled us to compare the effect of the AMA (coded 1) with those of the OLMA (coded -1) and NMA (coded -1). A preliminary analysis revealed that using the measures of average tapping time between two depressions and tapping ability in one model manifested a multi-colinearity (tolerance scores lower than 0.2 , which indicate an extensive overlap between the predictors). Therefore, we ran models in which we used only the measure of average tapping time between two depressions. The unstandardized regression coefficients for gross motor, fine motor and time estimation abilities are presented in Table 3. The analysis revealed that AMA conditions related to better locomotion, object control and time estimation abilities than both the NMA and OLMA conditions. The AMA group also demonstrated a 


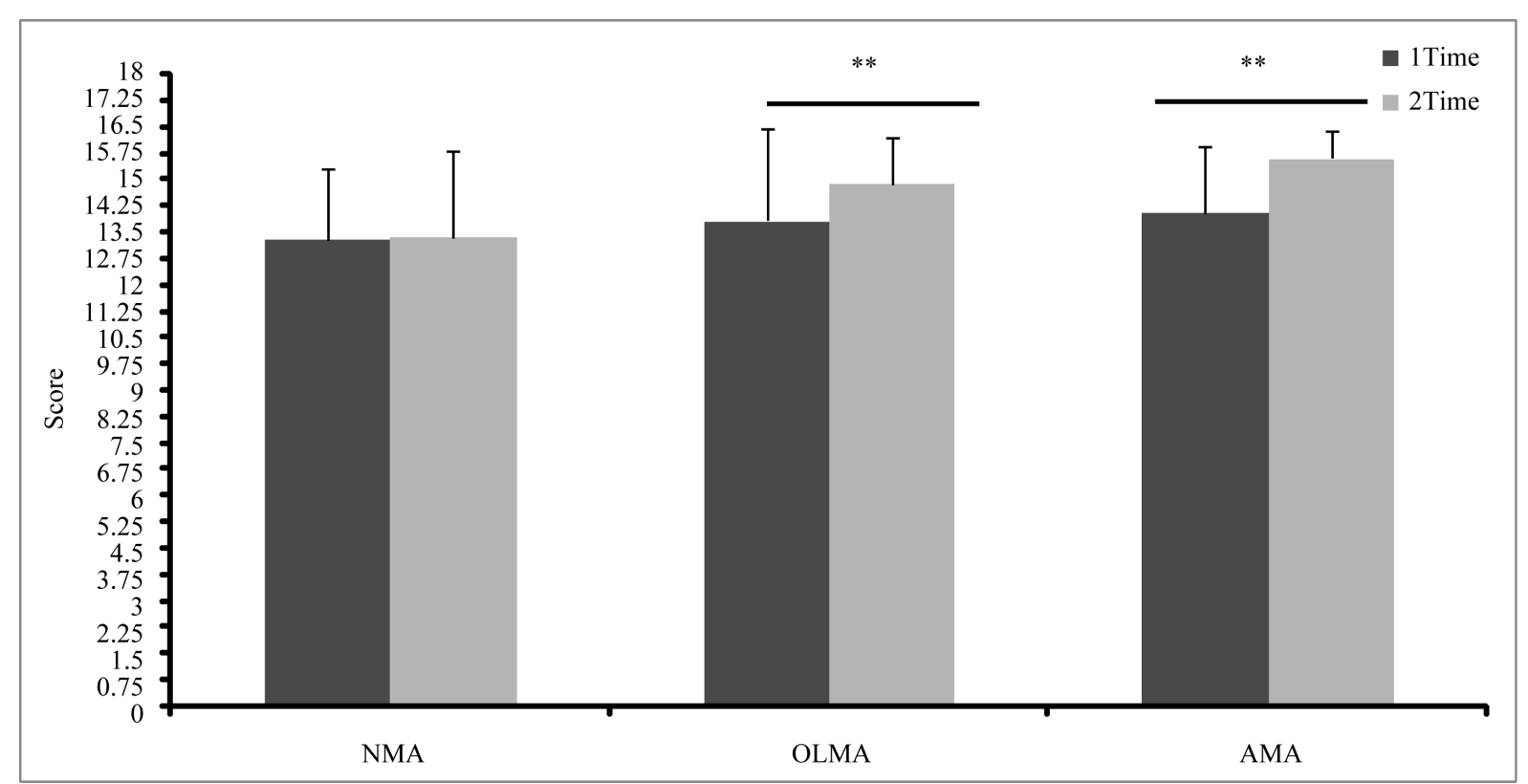

(a)

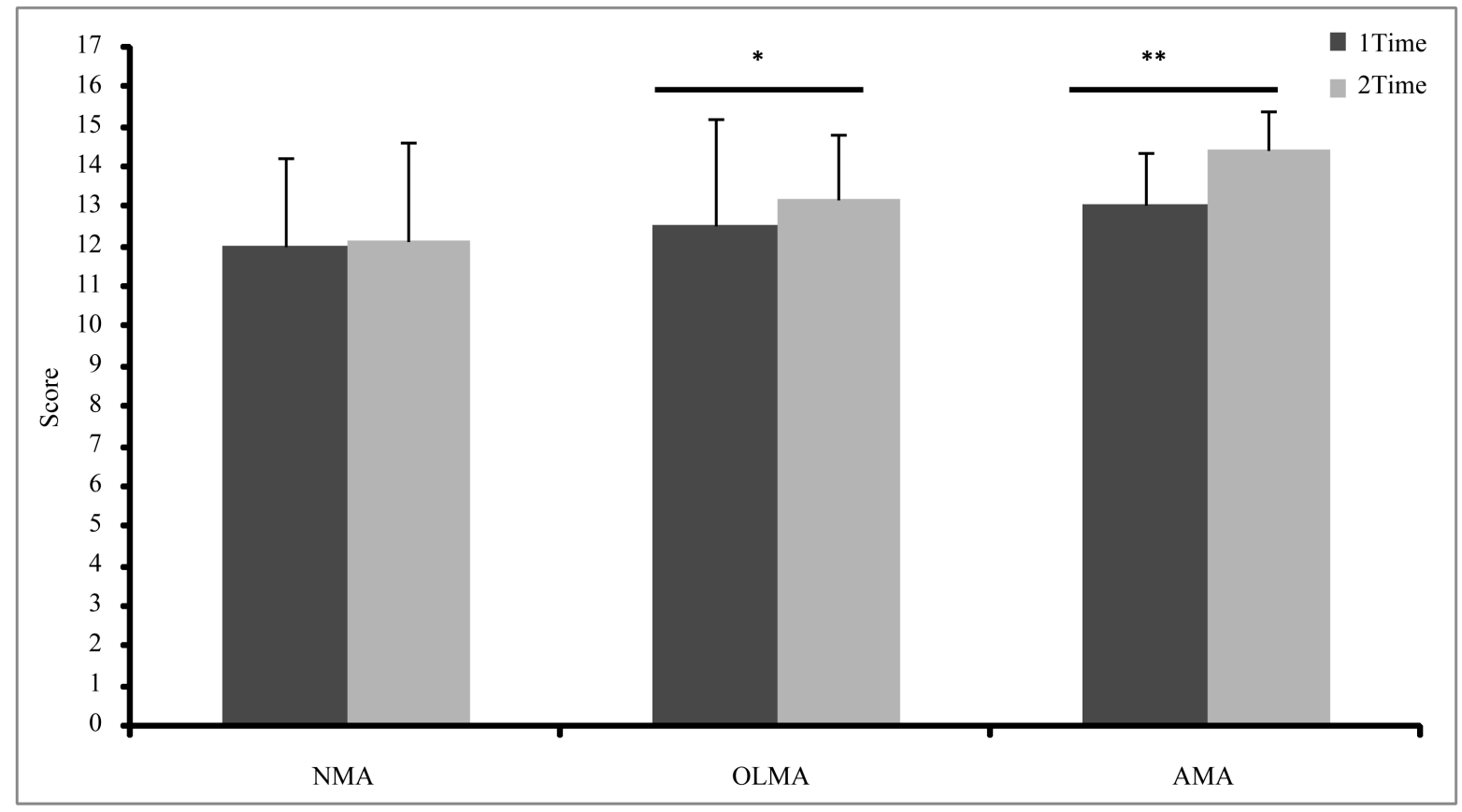

(b)

Figure 2. (a) Means and standard deviations for examining the differences in gross motor ability of locomotion as a function of time and study group. ${ }^{* *} p<0.01$. (b) Means and standard deviations for examining the differences in gross motor ability of object control as a function of time and study group. ${ }^{*} p<0.05, * * p<0.01$.

shorter tapping average duration between two depressions than the NMA group. Therefore, we continued to assess the mediation processes via these abilities.

Step II. Unstandardized regression coefficients are presented in Table 4. The analysis revealed that the AMA group demonstrated a better RCPM score than both the NMA and OLMA groups. In addition, the analysis revealed that the better the object-control abilities, the better the visual matching score. This effect was significantly above and beyond the contribution of the study group to the prediction. Moreover, the analysis revealed 


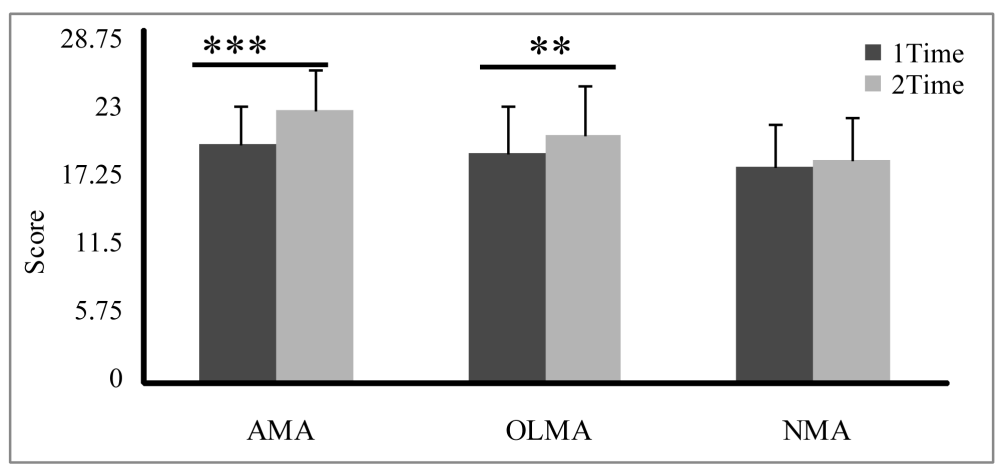

Figure 3. Means and standard deviations for examining the differences in time estimation ability as a function of time and study group. ${ }^{* *} p<0.01,{ }^{* * *} p<$ 0.001 .

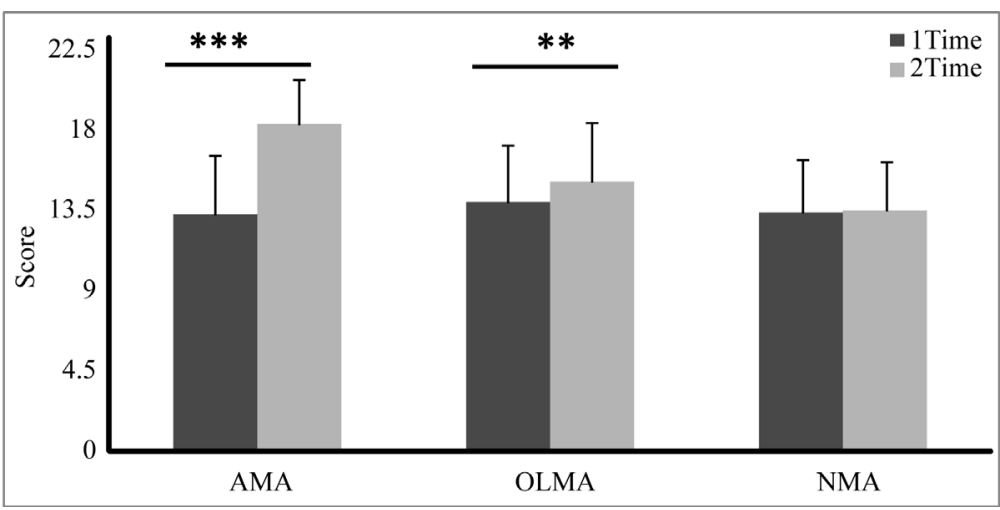

Figure 4. Means and standard deviations for examining the differences in cognitive ability of RCPM as a function of time and study group. ${ }^{* *} p<0.01, * * * p$ $<0.001$

Table 3. Unstandardized regression coefficients for predicting the change in the gross motor, fine motor and time estimation abilities by study group.

\begin{tabular}{cccccc}
\hline & Locomotion & Object Control & Finger-to-Thumb & Tapping-Average Duration & Time-Estimation \\
\hline AMA vs. NMA & $0.66^{* *}$ & $0.57^{* *}$ & -0.15 & $-0.29^{*}$ & $0.51^{* * *}$ \\
AMA vs. OLMA & $0.22^{*}$ & $0.32^{* *}$ & -0.09 & 0.02 & $0.29^{*}$ \\
\hline
\end{tabular}

Note: ${ }^{*} p<0.05, * * p<0.01$.

that the better the performance in the finger-to-thumb task, the better the performance in the cross-out task. Nevertheless, because the AMA group did not predict the performance in the finger-to-thumb task, a mediation process could not have occurred. The other paths were not significant. Therefore, we did not find that the change in the fine motor and time-estimation abilities over a period of six months mediated the effect of the AMA group on cognitive abilities.

Steps III to IV. The bias-corrected bootstrap analysis revealed that the mediation paths from the AMA (verses the OLMA training and/or NMA group) via object-control abilities to the participants' visual matching (95\% CI 0.01, 0.35 for AMA vs. NMA, 95\% CI 0.01, 0.19 for AMA vs. OLMA) was significant. In addition, as can be seen in Table 4, the links between AMA and the participants' visual matching was not significant after the inclusion of the object-control ability. Thus, the motor-related abilities fully mediated this path.

\section{Discussion}

The main objective of this study was to investigate the effects of AMA on motor, cognitive and time-estimation 
Table 4. Unstandardized regression coefficients for predicting the change in the cognitive abilities by gross motor, fine motor and time estimation abilities and study group.

\begin{tabular}{|c|c|c|c|}
\hline & Visual Matching & Cross-Out & $\mathrm{RCPM}$ \\
\hline Locomotion & -0.07 & -0.14 & -0.04 \\
\hline Object control & $0.27^{*}$ & 0.22 & 0.15 \\
\hline Finger-to-thumb & -0.42 & $-0.25^{*}$ & -0.03 \\
\hline Tapping-average duration & -0.13 & -0.05 & 0.03 \\
\hline Time-estimation & 0.03 & 0.03 & -0.01 \\
\hline AMA vs. NMA & 0.25 & 0.18 & $0.62^{* * *}$ \\
\hline AMA vs. OLMA & 0.03 & 0.17 & $0.86^{* * *}$ \\
\hline
\end{tabular}

Note: ${ }^{*} p<0.05,{ }^{* * *} p<0.001$.

abilities. To this aim, we compared the effects of AMA with two groups serving as controls for the motor and aquatic environment aspects of the AMA training, OLMA (representing the motor aspect of the training without the aquatic environment) and NMA (acting as a control for the motor aspect of the training). In addition, we explored whether the change in the motor abilities and time-estimation ability could explain changes in cognitive abilities.

First - and as expected - we found that gross motor abilities improved over time among the AMA and OLMA groups, but not among the NMA group. Gross motor skills are prerequisites for the performance of physical activities [49] [50]. Previous studies have demonstrated a positive relationship between gross motor skills and organized sports participation in children [49]. In addition, we found that AMA group demonstrated a connection to the development of significantly better gross motor abilities than the NMA group, while the OLMA group did not differ significantly from either the AMA group or the NMA group in this respect. On one hand, these results are in line with Becker [9], who claimed that aquatic training is unlikely to improve dry-land performance in coordination skills — such as hurdling, the high jump, or complex coordination activities - in comparison to onland intervention. On the other hand, Becker did not compare the results against non-motor intervention, and based his argument on research with adults; we suggest that the unique combination of high neuroplasticity during early childhood and the multi-sensory stimuli that characterize the aquatic environment are responsible for this difference. The aquatic environment activates a combination of the vestibular and the tactile systems [10], due to the unique characteristics of water such as density, hydrostatic pressure, and buoyancy [9]. The physical conditions of the aquatic environment allow for training at different depths and with differing gravitational influences on the individuals. Moreover, the aquatic environment provides three dimensions of movement rather than the two present on-land [51]. This results in more or new sensory information during AMA, which could account for the difference between the OLMA and AMA groups. Our results are also in line with Sato and colleagues [13], who suggested that aquatic immersion may enhance motor-related abilities. Sato and colleagues used functional near-infrared spectroscopy in their study, and found cortical activation in the primary somatosensory area (S1), parietal association area (PAA) and supplementary motor area (SMA) were induced by aquatic immersion. The SMA activation presumably related to the complex motor sequences and is closely related to the cerebellum [52].

Second, our findings indicate that the time estimation ability improved over time with the AMA and OLMA groups, but not with the NMA. Organizing and planning sequences of motor actions requires timing ability [29] [30]. The AMA group demonstrated better time estimation abilities than the NMA group, while the OLMA group did not differ significantly from either the AMA group or the NMA group in this respect. Our interpretation of this relates to the fact that in an aquatic environment, the child must coordinate between different kinds of rhythms: the kicking rhythm, the arms rhythm and the birthing rhythm. The simultaneity of these three different rhythms may develop motor timing and coordination. In addition, AMA provides multi-sensory stimulation which manifests a combination of the vestibular, proprioceptional and tactile sensory systems. The vestibular system in the inner ear reacts to head movements relative to gravity, and is connected to the cerebrum via the brain stem and cerebellum. The system operates in integration with the proprioceptive system and produces the 
sense of balance and stability. The vestibular system influences the regulation of muscle tension, body-movement coordination, and control of the eye movements which ensure a stable field of vision while moving [53]. The proprioceptive system refers to the sensation provided by muscles, ligaments and joints, and is created as a result of body movement. Proprioception allows ongoing awareness of posture and body movements in space, and the rhythm and timing of these movements [54]. Thus, it is a system providing external feedback to the cerebellum, allowing regulation of motor activity. The tactile system has receptors in the skin, serving as a mediator between self and environment. Thus, the tactile system provides the cerebellum with external feedback, allowing improved reaction time and precision of movement via the cerebellum.

Bisson, Tobin and Grondin [55] have claimed that literature concerning children's time-estimation is rather limited. According to the few studies available, children become more sensitive to time between the ages of three and eight [56] [57]. Timing processing is divided into motor timing and time perception. Motor timing refers to the timing aspects of motor acts, and time perception refers to the discriminative aspects of cognitive time management, such as the ability to estimate temporal delays [58]. The intermediate cerebellum, through its direct connections with the motor system, mediates the motor aspects of timing, while the lateral cerebellar hemispheres and their output nuclei mediate the cognitive or perceptual aspects of timing through their connections with the fronto-parietal association cortex [59]. However, functional neuro-imaging studies with healthy adults and with patients with cerebellar lesions showed the activation of both the medial and the lateral zones of the cerebellar cortex during tasks that required the precise representation of temporal information [60] [61]. Thus, it is still unclear if the cerebellar system mediates time-perception independently of motor behavior or other cognitive functions. Our findings suggest that in young children, time estimation is associated with motor activities and motor behavior. However, the manner by which these results relate to cerebellum function and neuroplasticity requires additional investigation. Our results expand the existing literature on children's time estimation by shedding further light regarding connection between this and motor training, and especially to AMA.

Third, the analysis revealed that the AMA group presented a better RCPM score in comparison to the NMA group. These results partially confirm our third hypothesis, and are congruent with several meta-analytic reviews of research studies that found various cognition assessments (e.g. perceptual skills, intellectual quotient scores and academic achievement) are positively related to physical activity in children [6] [62]. In connection with this, our findings suggest that AMA particularly improve RCPM scores. The RCPM tap general problem-solving skills [63]. There is increasing interest in the abilities required for problem-solving, and some experts have argued that problem-solving is connected to working-memory and fluid intelligence (also known as novel reasoning) [64] [65]. Working memory is a system for holding and manipulating information over brief periods of time, in the course of ongoing cognitive activities [66]. Fluid intelligence is the ability to reason under novel conditions, and stands in contrast to performance based on learned knowledge and skills or crystallized intelligence [67]. Neuropsychological studies have found that the RCPM task is related to prefrontal functioning, and that specific activity can be localized to the dorsolateral prefrontal cortex and posterior parietal cortex [68] [69]. In addition, co-activation of dorsolateral prefrontal cortex and the cerebellum has been repeatedly found to be related to several working-memory tasks [70] [71]. Our findings may thus serve as the basis for a new program of interventions for cerebellar-related neurodevelopmental disorders with impaired working-memory and fluid intelligence mechanism. This mechanism has been found to be impaired among population with mental retardation [72] [73]. In addition, studies discussing the "Cerebellar Deficit Hypothesis" of dyslexia suggest that cerebellar deficits can affect articulation and working memory [33].

Finally, we succeeded in demonstrating that the mediation paths from the AMA (verses the OLMA training and/or NMA group) via object-control abilities to participants' visual matching were significant. With regard to gross motor abilities, according to Latash and Turvey [74], locomotion abilities are supposed to be more automatized and less dependent on cognitive functioning, while object-control abilities are supposed to require more involvement of cognitive processes. Processing speed ability is closely related to reading [75]-[77] and writing [78]. Studies have indicated that processing speed (as measures in the visual matching task) is further related to the orthographic processes that are important for reading during childhood and adolescence [75]. Our novel findings shed light on the normal development of the cognitive-related abilities that emphasize the importance of motor functioning. Moreover, intervention that enhances gross motor functions will lead to improvements in visual matching. The combination of this specific information concerning the advantages of an aquatic environment for children may provide useful knowledge for physical-education teachers, and can be utilized in the development of motor interventions for pre-school children. For instance, object control is a specific element of 
gross motor skills found to be associated with the development of processing speed, over time, in kindergarten; this would suggest that children's processing speed abilities may benefit from more explicit programs enhancing object control abilities, such as aquatic motor intervention.

There are several limitations to this study that should be acknowledged. First, the small sample size limited the power of the study and prevented further sub-analyses of gender differences, or of children with a family history of learning disabilities. Further research, with larger sample sizes, is needed to address these issues. Second, eligibility was determined by parental report, which may be misrepresented. Third, we are aware of the potential differences between the various types of non-aquatic motor and non-motor activities which were used in the study. Future research will examine specific different elements of the aquatic training, including the differing effect of gravity at different depths, and activities in three dimensions of movement. However, we should keep in mind that this is a preliminary exploratory research, aimed at examining the potential effect of aquatic environments and the relationship between AMA and cognitive abilities in normal populations during early childhood. Fourth, we refer to gross motor, fine motor and time-estimation abilities as "cerebellum-related" abilities. This claim should be accompanied by an examination of the effect of exercise on brain morphology and internal connectivity, using Magnetic Resonance Imaging or Track-Density Imaging. Further research is needed, incorporating this possibility for the validation of our hypothesis, and we are currently working in this direction.

\section{Conclusion}

In conclusion, the current research provides evidence that AMA can be useful in improving the motor, cognitive and time-estimation abilities in children aged between four and six attending standard kindergartens. It thus contributes to the understanding of the possibilities afforded by different motor training and the possible neural mechanisms that underpin the enhancement of these abilities. The advantages of an aquatic environment for children may further provide useful knowledge for physical-education teachers and could be utilized in the development of motor interventions for pre-school children. In addition, such interventions may help reduce early motor difficulties, thereby preventing additional motor disorders which can lead to associated emotional, social and educational problems. The interpretation of the current findings - and their relation with previous findings linking cognitive abilities to the cerebellum - may explain how aquatic motor activity (AMA) may be responsible for the enhancement of motor and cognitive abilities. In turn, the findings may serve as the basis for a new intervention program for different developmental disorders. This could specifically be the case with both dyslexia - where the cerebellar deficits can affect articulation and working memory [33] — and with mental retardation [72] [73], where the subjects are known to suffer from impaired working-memory and fluid intelligence. This is particularly relevant given that early childhood is the most cost-effective period for long-term interventions [79], and that during early-childhood there is greater efficiency in neuroplasticity [15].

\section{Acknowledgements}

The results of this research are part of Michal Nissim's thesis, in partial fulfillment of the requirements toward her Ph.D. degree at Bar-Ilan University.

Michal Nissim is grateful to the Azrieli Foundation for the award of an Azrieli Fellowship.

The authors would also wish to thank the Chief Scientist of the Ministry of Education, Israel, for approval and support in conducting this research.

\section{References}

[1] Ben-Soussan, T.D., Glicksohn, J., Goldstein, A., Berkovich-Ohana, A. and Donchin, O. (2013) Into the Square and Out of the Box: The Effects of Quadrato-Motor Training on Creativity and Alpha Coherence. PloS ONE, 8, e55023. http://dx.doi.org/10.1371/journal.pone.0055023

[2] Warburton, D.E., Nicol, C.W. and Bredin, S.S. (2006) Health Benefits of Physical Activity: The Evidence. Canadian Medical Association Journal, 174, 801-809. http://dx.doi.org/10.1503/cmaj.051351

[3] Wassenberg, R., Feron, F., Kessels, A., Hendriksen, J., Kalff, A., Kroes, M., Hurks, P.P., Beeren, M., Jolles, J. and Vles, J. (2005) Relation between Cognitive and Motor Performance in 5- to 6-Year-Old Children: Results from a Large-Scale Cross-Sectional Study. Child Development, 76, 1092-1103. http://dx.doi.org/10.1111/j.1467-8624.2005.00899.x

[4] Diamond, A. (2005) Attention Deficit Disorder (Attention-Deficit/Hyperactivity Disorder without Hyperactivity): A 
Neurobiologically and Behaviorally Distinct Disorder from Attention-Deficit/Hyperactivity Disorder (with Hyperactivity). Development and Psychopathology, 17, 807-825. http://dx.doi.org/10.1017/S0954579405050388

[5] Diamond, A. (2000) Close Interrelation of Motor Development and Cognitive Development and of the Cerebellum and Prefrontal Cortex. Child Development, 71, 44-56. http://dx.doi.org/10.1111/1467-8624.00117

[6] Sibley, B.A. and Etnier, J.L. (2003) The Relationship between Physical Activity and Cognition in Children: A Meta-Analysis. Pediatric Exercise Science, 15, 243-256.

[7] Hillman, C.H., Erickson, K.I. and Kramer, A.F. (2008) Be Smart, Exercise Your Heart: Exercise Effects on Brain and Cognition. Nature Reviews Neuroscience, 9, 58-65. http://dx.doi.org/10.1038/nrn2298

[8] Smith, L.B. and Thelen, E. (2003) Development as a Dynamic System. Trends in Cognitive Sciences, 7, 343-348. http://dx.doi.org/10.1016/S1364-6613(03)00156-6

[9] Becker, B.E. (2009) Aquatic Therapy: Scientific Foundations and Clinical Rehabilitation Applications. American Academy of Physical Medicine and Rehabilitation, 1, 859-872. http://dx.doi.org/10.1016/j.pmrj.2009.05.017

[10] Devereux, K., Robertson, D. and Briffa, N.K. (2005) Effects of a Water-Based Program on Women 65 Years and over: A Randomized Controlled Trial. Australian Journal of Physiotherapy, 51, 102-108. http://dx.doi.org/10.1016/S0004-9514(05)70038-6

[11] Roth, A.E., Miller, M.G., Ricard, M., Ritenour, D. and Chapman, B.L. (2006) Comparisons of Static and Dynamic Balance Following Training in Aquatic and Land Environments. Journal of Sport Rehabilitation, 15, 299-311.

[12] Lakoff, G. and Johnson, M. (1999) Philosophy in the Flesh: The Embodied Mind and Its Challenges to Western thought. Basic Books, New York.

[13] Sato, D., Yamashiro, K., Onishi, H., Shimoyama, Y., Yoshida, T. and Maruyama, A. (2012) The Effect of Water Immersion on Short-Latency Somatosensory Evoked Potentials in Human. BMC Neuroscience, 13, 13-19. http://dx.doi.org/10.1186/1471-2202-13-13

[14] Pascual-Leone, A., Amedi, A., Fregni, F. and Merabet, L.B. (2005) The Plastic Human Brain Cortex. Annual Review of Neuroscience, 28, 377-401. http://dx.doi.org/10.1146/annurev.neuro.27.070203.144216

[15] Hannaford, C. (2005) Smart Moves: Why Learning Is Not All in Your Head. 2nd Edition, Great Ocean Books, Arlington.

[16] Stoodley, C.J. and Schmahmann, J.D. (2009) Functional Topography in the Human Cerebellum: A Meta-Analysis of Neuroimaging Studies. NeuroImage, 44, 489-501. http://dx.doi.org/10.1016/j.neuroimage.2008.08.039

[17] Dow, R. and Moruzzi, G. (1958) The Physiology and Pathology of the Cerebellum. University of Minnesota Press, Minneapolis.

[18] Holmes, G. (1939) The Cerebellum of Man. Brain, 62, 1-30. http://dx.doi.org/10.1093/brain/62.1.1

[19] Bastian, A.J. (2006) Learning to Predict the Future: The Cerebellum Adapts Feedforward Movement Control. Current Opinion in Neurobiology, 16, 645-649. http://dx.doi.org/10.1016/j.conb.2006.08.016

[20] Wolpert, D.M., Miall, R.C. and Kawato, M. (1998) Internal Models in the Cerebellum. Trends in Cognitive Sciences, 2, 313-321. http://dx.doi.org/10.1016/S1364-6613(98)01221-2

[21] Stoodley, C.J. and Stein, J.F. (2013) Cerebellar Function in Developmental Dyslexia. The Cerebellum, 12, 267-276. http://dx.doi.org/10.1007/s12311-012-0407-1

[22] Durisko, C. and Fiez, J. (2010) Functional Activation in the Cerebellum during Working Memory and Simple Speech Tasks. Cortex, 46, 896-906. http://dx.doi.org/10.1016/j.cortex.2009.09.009

[23] Fuster, J.M., Bodner, M. and Kroger, J.K. (2000) Cross-Modal and Cross-Temporal Association in Neurons of Frontal Cortex. Nature, 405, 347-351. http://dx.doi.org/10.1038/35012613

[24] Marvel, C.L., Faulkner, M.L., Strain, E.C., Mintzer, M.Z. and Desmond, J.E. (2012) An fMRI Investigation of Cerebellar Function during Verbal Working Memory in Methadone Maintenance Patients. Cerebellum, 11, 300-310. http://dx.doi.org/10.1007/s12311-011-0311-0

[25] Narayanan, N.S. and Laubach, M. (2006) Top-Down Control of Motor Cortex Ensembles by Dorsomedial Prefrontal Cortex. Neuron, 52, 921-931. http://dx.doi.org/10.1016/j.neuron.2006.10.021

[26] Harrington, D.L. and Haaland, K.Y. (1999) Neural Underpinnings of Temporal Processing: A Review of Focal Lesion, Pharmacological, and Functional Imaging Research. Review of Neuroscience, 10, 91-116. http://dx.doi.org/10.1515/REVNEURO.1999.10.2.91

[27] Ivry, R.B. and Keele, S.W. (1989) Timing Functions of the Cerebellum. Journal of Cognitive Neuroscience, 1, $136-152$. http://dx.doi.org/10.1162/jocn.1989.1.2.136

[28] Ivry, R.B. and Diener, H.C. (1991) Impaired Velocity Perception in Patients with Lesions of Cerebellum. Journal of Cognitive Neuroscience, 3, 355-366. http://dx.doi.org/10.1162/jocn.1991.3.4.355 
[29] Hazeltine, E., Helmut, L.L. and Ivry, R.B. (1998) Neural Mechanisms of Timing. Trends in Cognitive Science, 1, 163169. http://dx.doi.org/10.1016/S1364-6613(97)01058-9

[30] Ivry, R.B. (1997) Cerebellar Timing Systems. International Review of Neurobiology, 41, 555-573. http://dx.doi.org/10.1016/S0074-7742(08)60370-0

[31] McCrory, C. and Cooper, C. (2005) The Relationship between Three Auditory Inspection Time Tasks and General Intelligence. Personality and Individual Differences, 38, 1835-1845. http://dx.doi.org/10.1016/j.paid.2004.11.012

[32] Laycock, S.K., Wilkinson, I.D., Wallis, L.I., Darwent, G., Wonders, S.H., Fawcett, A.J. and Nicolson, R.I. (2008) Cerebellar Volume and Cerebellar Metabolic Characteristics in Adults with Dyslexia. Annals of the New York Academy of Sciences, 1145, 222-236. http://dx.doi.org/10.1196/annals.1416.002

[33] Nicolson, R.I., Fawcett, A.J. and Dean, P. (2001) Developmental Dyslexia: The Cerebellar Deficit Hypothesis. Trends in Neurosciences, 24, 515-516. http://dx.doi.org/10.1016/S0166-2236(00)01896-8

[34] Nicolson, R.I. and Fawcett, A.J. (1990) Automaticity: A New Framework for Dyslexia Research? Cognition, 35, 159182. http://dx.doi.org/10.1016/0010-0277(90)90013-A

[35] Nicolson, R.I., Fawcett, A.J. and Dean, P. (1995) Time Estimation Deficits in Developmental Dyslexia: Evidence of Cerebellar Involvement. Proceedings of the Royal Society B: Biological Sciences, 259, 43-47. http://dx.doi.org/10.1098/rspb.1995.0007

[36] Fernandez, V.G., Stuebing, K., Juranek, J. and Fletcher, J.M. (2013) Volumetric Analysis of Regional Variability in the Cerebellum of Children with Dyslexia. Cerebellum, 12, 906-915. http://dx.doi.org/10.1007/s12311-013-0504-9

[37] Berger, S.E. (2010) Locomotor Expertise Predicts Infants' Perseverative Errors. Developmental Psychology, 46, 326336. http://dx.doi.org/10.1037/a0018285

[38] Brody, L.T. and Geigle, P.R. (2009) Aquatic Exercise for Rehabilitation and Training. Human Kinetics, Champaign.

[39] McMillan, J. (1978) The Role of Water in Rehabilitation. Fysioterapeuten, 45, 87-90.

[40] Ulrich, D.A. (1985) Test of Gross Motor Development. Pro-ED, Austin.

[41] Hutzler, Y. (1996) Assessment of Motor Abilities in School-Age Children: Theoretical Aspects. Part 1. Journal of Sports and Physical Education, 1, 15-18. (Hebrew)

[42] Hutzler, Y. (1996) Assessment of Motor Abilities in School-Age Children: Recommendations for Grades 1-4. Journal of Sports and Physical Education, 2, 22-25. (Hebrew)

[43] Denckla, M.B., Rudel, R.G., Chapman, C. and Krieger, J. (1985) Motor Proficiency in Dyslexic Children with and without Attentional Disorders. Archives of Neurology, 42, 228-231. http://dx.doi.org/10.1001/archneur.1985.04060030042008

[44] Raven, J.C. (1965) Guide to Using the Coloured Progressive Matrices Sets A, Ab, B. (Revised Order, 1956). H.K. Lewis, London.

[45] Woodcock, R.W. and Johnson, M.B. (1989) Woodcock-Johnson Psycho-Educational Battery-Revised. DLM. Allen, TX.

[46] Preacher, K.J. and Hayes, A.F. (2008) Asymptotic and Resampling Strategies for Assessing and Comparing Indirect Effects in Multiple Mediator Models. Behavior Research Methods, 40, 879-891. http://dx.doi.org/10.3758/BRM.40.3.879

[47] Baron, R. and Kenny, D.A. (1986) The Moderator-Mediator Variable Distinction in Social Psychological Research: Conceptual, Strategic, and Statistical Considerations. Journal of Personality and Social Psychology, 51, 1173-1182. http://dx.doi.org/10.1037/0022-3514.51.6.1173

[48] Preacher, K.J., Zyphur, M.J. and Zhang, Z. (2010) A General Multilevel SEM Framework for Assessing Multilevel Mediation. Psychological Methods, 15, 209-233. http://dx.doi.org/10.1037/a0020141

[49] Barnett, L.M., van Beurden, E., Morgan, P.J., Brooks, L.O. and Beard, J.R. (2009) Childhood Motor Skill Proficiency as a Predictor of Adolescent Physical Activity. The Journal of Adolescent Health, 44, 252-259. http://dx.doi.org/10.1016/j.jadohealth.2008.07.004

[50] Graf, C., Koch, B., Kretschmann-Kandel, E., Falkowski, G., Christ, H., Coburger, S., Lehmacher, W., Bjarnason-Wehrens, B., Platen, P., Tokarski, W., Predel, H.G. and Dordel, S. (2004) Correlation between BMI, Leisure Habits and Motor Abilities in Childhood (Child-Project). International Journal of Obesity, 28, 22-26. http://dx.doi.org/10.1038/sj.ijo.0802428

[51] Ram-Tsur, R., Nissim, M., Zion, M., Dotan Ben-Soussan, T. and Mevarech, Z.A. (2013) Language Development: The Effect of Aquatic and On-Land Motor Interventions. Creative Education, 4, 41-50. http://dx.doi.org/10.4236/ce.2013.49B009

[52] Pennington, B.F. (1999) Toward an Integrated Understanding of Dyslexia: Genetic, Neurological, and Cognitive Me- 
chanisms. Development and Psychopathology, 11, 629-654. http://dx.doi.org/10.1017/S0954579499002242

[53] Bundy, A.C. and Murray, A.E. (2002) Sensory Integration: A. Jean Ayres’ Theory Revisited. In: Bundy, A.C., Lane, S.J. and Murray, E.A., Eds., Sensory Integration: Theory and Practice, 2nd Edition, F. A Davis, Philadelphia, 3-33.

[54] Williamson, G.G. and Anzalone, M.E. (2001) Sensory Integration and Self-Regulation in Infants and Toddlers: Helping Very Young Children Interact with Their Environment. Zero to Three, Washington DC.

[55] Bisson, N., Tobin, S. and Grondin, S. (2012) Prospective and Retrospective Time Estimates of Children: A Comparison Based on Ecological Tasks. PLoS ONE, 7, e33049. http://dx.doi.org/10.1371/journal.pone.0033049

[56] Droit-Volet, S. (2003) Temporal Experience and Timing in Children. In: Meck, W.H., Ed., Functional and Neural Mechanisms of Interval Timing, CRC Press, Boca Raton, 183-208. http://dx.doi.org/10.1201/9780203009574.ch7

[57] Gautier, T. and Droit-Volet, S. (2002) Attention and Time Estimation in 5- and 8-Year-Old Children: A Dual Task Procedure. Behavioral Processes, 58, 57-66. http://dx.doi.org/10.1016/S0376-6357(02)00002-5

[58] Fuster, J.M. (1990) Prefrontal Cortex and the Bridging of Temporal Gaps in the Perception-Action Cycle. Annals of the New York Academy of Sciences, 608, 318-329. http://dx.doi.org/10.1111/j.1749-6632.1990.tb48901.x

[59] Middleton, F.A. and Strick, P.L. (1994) Anatomical Evidence for Cerebellar and Basal Ganglia Involvement in Higher Cognitive Function. Science, 266, 458-461. http://dx.doi.org/10.1126/science.7939688

[60] Ramnani, N. and Passingham, R.E. (2001) Changes in the Human Brain during Rhythm Learning. Journal of Cognitive Neuroscience, 13, 952-966. http://dx.doi.org/10.1162/089892901753165863

[61] Harrington, D.L., Boyd, L.A., Mayer, A.R., Sheltraw, D.M., Lee, R.R., Huang, M. and Rao, S.M. (2004) Neural Representation of Interval Encoding and Decision Making. Cognitive Brain Research, 21, 193-205. http://dx.doi.org/10.1016/j.cogbrainres.2004.01.010

[62] Tomporowski, P.D., Davis, C.L., Miller, P.H. and Naglieri, J.A. (2008) Exercise and Children's Intelligence, Cognition, and Academic Achievement. Educational Psychology Review, 20, 111-131. http://dx.doi.org/10.1007/s10648-007-9057-0

[63] Davis, F.A., Carpenter, P.A., Just, M.A. and Shell, P. (1990) What One Intelligence Test Measures: A Theoretical Account of Processing in the Raven Progressive Matrices Test. Psychological Review, 97, 404-431. http://dx.doi.org/10.1037/0033-295X.97.3.404

[64] Gignac, G.E. (2007) Working Memory and Fluid Intelligence Are Both Identical to Reanalyses and Critical Evaluation. Psychology Science, 49, 187-207.

[65] Salthouse, T.A. and Pink, J.E. (2008) Why Is Working Memory Related to Fluid Intelligence? Psycholomic Bulletin and Review, 15, 364-371. http://dx.doi.org/10.3758/PBR.15.2.364

[66] Engel de Abreu, P.M.J., Conway, A.R.A. and Gathercole, S.E. (2010) Working Memory and Fluid Intelligence in Young Children. Intelligence, 38, 552-561. http://dx.doi.org/10.1016/j.intell.2010.07.003

[67] Haavisto, M.L. and Lehto, J.E. (2005) Fluid/Spatial and Crystallized Intelligence in Relation to Domain-Specific Working Memory: A Latent-Variable Approach. Learning and Individual Differences, 15, 1-21. http://dx.doi.org/10.1016/j.lindif.2004.04.002

[68] Christoff, K., Prabhakaran, V., Dorfman, J., Zhao, Z., Kroger, J.K., Holyoak, K.J. and Gabrieli, J.D.E. (2001) Rostrolateral Prefrontal Cortex Involvement in Relational Integration during Reasoning. Neuroimage, 14, 1136-1149. http://dx.doi.org/10.1006/nimg.2001.0922

[69] Kroger, J.K., Sabb, F.W., Fales, C.L., Bookheimer, S.Y., Cohen, M.S. and Holyoak, K.J. (2002) Recruitment of Anterior Dorsolateral Prefrontal Cortex in Human Reasoning: A Parametric Study of Relational Complexity. Cerebral Cortex, 12, 477-485. http://dx.doi.org/10.1093/cercor/12.5.477

[70] Salmi, J., Pallesen, K.J., Neuvonen, T., Brattico, E., Korvenoja, A., Salonen, O. and Carlson, S. (2010) Cognitive and Motor Loops of the Human Cerebro-Cerebellar System. Journal of Cognitive Neuroscience, 22, 2663-2676. http://dx.doi.org/10.1162/jocn.2009.21382

[71] Stoodley, C.J., Valera, E.M. and Schmahmann, J.D. (2012) Functional Topography of the Cerebellum for Motor and Cognitive Tasks: An fMRI Study. Neuroimage, 59, 1560-1570. http://dx.doi.org/10.1016/j.neuroimage.2011.08.065

[72] Hulme, C. and Mackenzie, S. (1992) Working Memory and Sever Learning Difficulties. Erlbaum, Hillsdale.

[73] Pulsifer, M.B. (1996) The Neuropsychology of Mental Retardation. Journal of the International Neuropsychological Society, 2, 159-176. http://dx.doi.org/10.1017/S1355617700001016

[74] Latash, M.L. and Anson, J.G. (1996) What Are "Normal Movements" in Atypical Populations? Behavioral and Brain Sciences, 19, 55-106. http://dx.doi.org/10.1017/S0140525X00041467

[75] Evans, J.J., Floyd, R.G., McGrew, K.S. and LeForgee, M.H. (2002) The Relations between Measures of CattellHorn-Carroll (CHC) Cognitive Abilities and Reading Achievement during Childhood and Adolescence. School Psy- 
chology Review, 31, 246-262.

[76] McGrew, K.S. and Knopik, S.N. (1993) The Relationship between the WJ-RGf-Gc Cognitive Clusters and Writing Achievement across the Life-Span. School Psychology Review, 22, 687-695.

[77] Ram-Tsur, R., Faust, M. and Zivotofsky, A.Z. (2008) Poor Performance on Serial Visual Tasks in Persons with Reading Disabilities: Impaired Working Memory? Journal of Learning Disabilities, 41, 437-450. http://dx.doi.org/10.1177/0022219408321141

[78] Floyd, R.G., McGrew, K.S. and Evans, J.J. (2008) The Relative Contributions of the Cattell-Horn-Carroll Cognitive Abilities in Explaining Writing Achievement during Childhood and Adolescence. Psychology in the Schools, 45,132-144. http://dx.doi.org/10.1002/pits.20284

[79] Reynolds, A.J., Temple, J.A., Robertson, D.L. and Mann, E.A. (2001) Long-Term Effects of an Early Childhood Intervention on Educational Achievement. Journal of the American Medical Association, 285, 2339-2346.

http://dx.doi.org/10.1001/jama.285.18.2339 
Scientific Research Publishing (SCIRP) is one of the largest Open Access journal publishers. It is currently publishing more than 200 open access, online, peer-reviewed journals covering a wide range of academic disciplines. SCIRP serves the worldwide academic communities and contributes to the progress and application of science with its publication.

Other selected journals from SCIRP are listed as below. Submit your manuscript to us via either submit@scirp.org or Online Submission Portal.
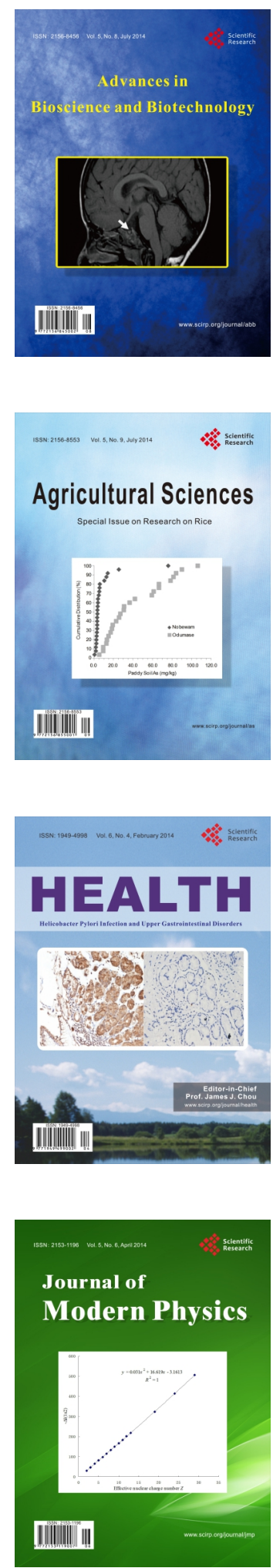
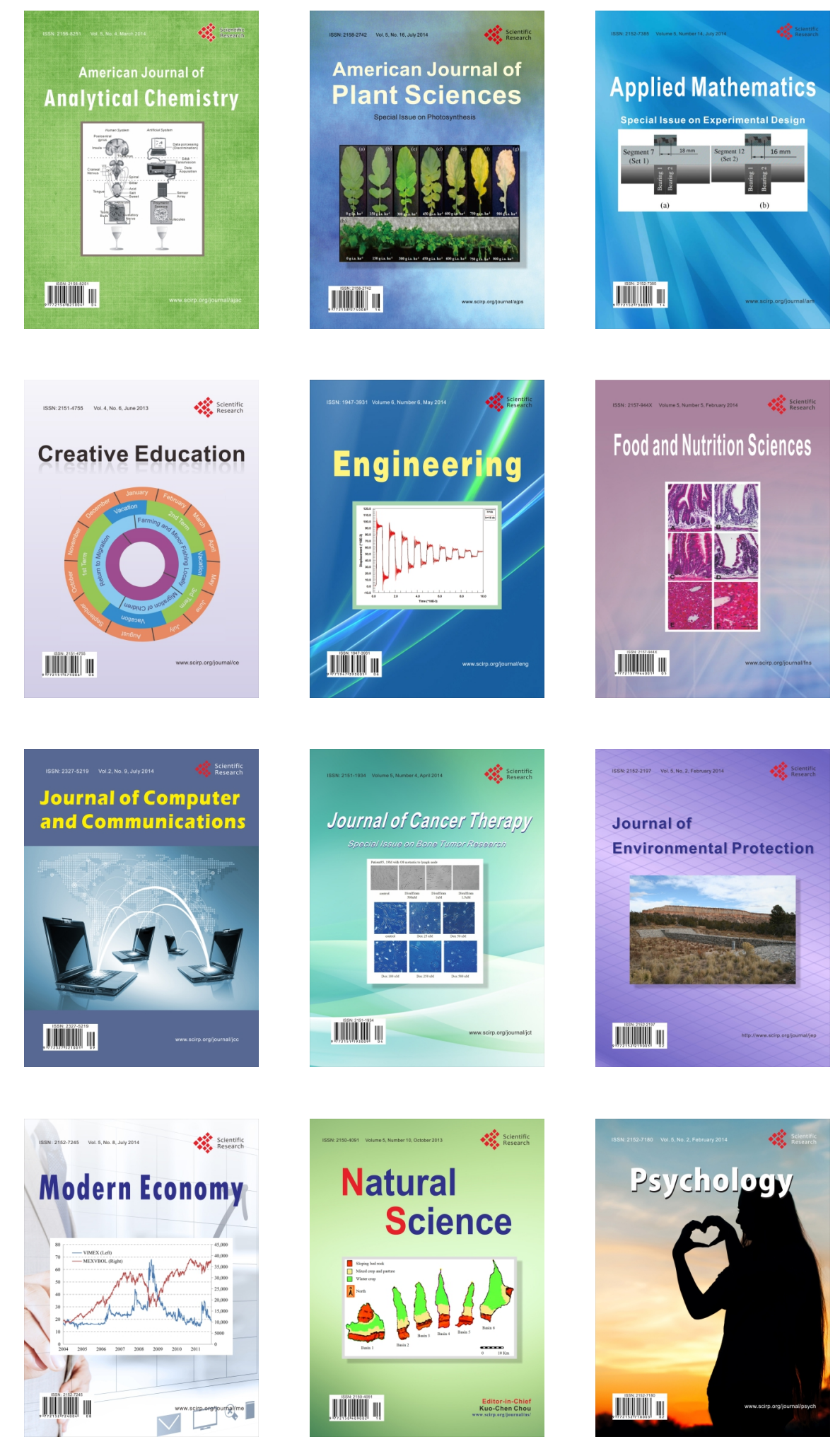